\title{
Effect of hydrogen in aluminium and aluminium alloys: A review
}

\author{
RAJAN AMBAT and E S DWARAKADASA \\ Centre for Advanced Study, Department of Metallurgy, Indian Institute of Science, Bangalore \\ 560012 , India \\ Hbstract. Susceptibility of aluminium and its alloys towards hydrogen embrittlement has \\ been well established. Still a lot of confusion exists on the question of transport of hydrogen \\ and its possible role in stress corrosion cracking. This paper reviews some of the fundamental \\ properties of hydrogen in aluminium and its alloys and its effect on mechanical properties. The \\ importance of hydrogen embrittlement over anodic dissolution to explain the stress corrosion \\ cracking mechanism of these alloys is also examined in considerable detail. The various \\ experimental findings concerning the link between hydrogen embrittlement and stress cor- \\ rosion cracking are also discussed.
}

Keywords. Hydrogen embrittlement; stress corrosion cracking; aluminium alloys.

\section{Introduction}

Aluminium alloys are getting renewed altention because of the possibility of further improvement in the strength-to-weight ratio in competition with composites, intermetallics and titanium alloys. Performance characteristics of these materials depend greatly on various environmental factors; an important one being the susceptibility towards hydrogen. The susceptibility of aluminium and its alloys towards hydrogen embrittlement has been proved beyond doubt (Gest and Troiano 1974; Scamans 1978; Christodoulou and Flower 1980; Albrecht et al 1982; Hardwick et al 1983; Tuck 1985; Wu-yang Chu et al 1985; Watson et al 1988). It has also been well accepted that the hydrogen embrittlement plays a key role in stress corrosion cracking, the major concern in technological application of high-strength aluminium alloys (Troiano 1960; Speidel 1971; Watson and Meshii 1989). The multifaceted effects of hydrogen on the mechanical properties of aluminium alloys have to be understood clearly in terms of microstructure, alloying additions etc. in order to tackle the problem. This paper briefly reviews some of the aspects of the solubility of hydrogen in aluminium, its effect on mechanical properties and also its role in stress corrosion cracking (SCC).

\section{Solubility of hydrogen in pure aluminium}

The solubility of hydrogen in pure crystalline aluminium is relatively small. At room temperature, the value was reported (Ransley and Neufeld 1948; Opie and Grant 1950; Eichenauer et al 1961; Talbot 1975) to be about $1.5 \times 10^{-12}$ atomic fraction. The solubility at the melting point was found to be about $10^{-6}$ atomic fraction and it decreases rapidly with temperature. Hydrogen occupies interstitial position in aluminium alloys causing expansion of the crystal lattices (Watson and Meshii 1989). Partial molar volume of hydrogen is reported (Peisl 1978) to be $2.9 \AA^{3}$ which tallies with the value for many face-centred cubic metals and alloys. This value remained constant over a wide range of concentration. 
A number of investigators have attempted to study the diffusion of hydrogen in aluminium (Eichenauer and Pebler 1957; Matsuo and Hirata 1967; Papp and KovacsCseteny 1977, 1981; Ichimura et al 1980; Csnady et al 1981; Outlaw et al 1982; Hashimoto and Kino 1983; Ishikawa and Mc Lellan 1986). The work of Ishikawa and Mc Lellan (1986) in the temperature range of 285 to $328 \mathrm{~K}$, indicated that a single Arrhenius relation can represent the diffusivities they obtained in this temperature range as well as those determined in the high-temperature range up to the melting point. The best fit was obtained by

$$
D\left(m^{2} / \mathrm{s}\right)=9.2 \times 10^{-5} \exp \frac{(-55250 \mathrm{~J} / \mathrm{mol})}{R T}
$$

where $D$ is the diffusivity of hydrogen in aluminium, $R$ is the gas constant in $\mathrm{Jmol}^{-1} \mathrm{~K}^{-1}$ and $T$ temperature in Kelvin.

The solubility and the diffusivity of hydrogen can be influenced significantly by trapping of hydrogen by lattice defects. As a result, the effect of hydrogen on various properties should be interpreted taking into consideration the hydrogen trapping sites.

Various types of defects in the crystals such as lattice vacancies, dislocations and grain boundaries provide potential trapping sites for hydrogen (Watson and Meshii 1989). Sometimes certain types of solute atom clusters can also trap hydrogen. It can also be found in the form of gas bubbles if its local concentration reaches above a critical value (Scamans 1978; Albrecht et al 1982). The hydrogen induced porosity is one of the major problem associated with aluminium casting industry (Ransley and Neufeld 1948; Shahani 1985; Tiwari et al 1986). The binding energy between vacancies and hydrogen has been reported to be around $0.5 \mathrm{eV}(48.1 \mathrm{KJ} / \mathrm{mol})$ (Besenbacher et al 1986). Radiographic observation of the distribution of tritium in zone refined aluminium by Foster et al (1970) by charging with tritium at elevated temperatures ( 500 or $600^{\circ} \mathrm{C}$ ) and subsequent radiographic analysis showed segregation of tritium on dislocations, cell and grain boundaries. Edvards and Eichenauer (1980) observed a decline in solubility of hydrogen as grain growth increases due to the reduction in grain boundary area indicating grain boundary segregation of hydrogen. The binding enthalpy between hydrogen and grain boundary is reported to be $14 \mathrm{KJ} / \mathrm{mol}(0 \cdot 15 \mathrm{eV})$ (Leger and Piercy 1981) which is much less than that obtained for vacancies $(0.5 \mathrm{eV})$.

There are certain discrepancies in the nature of hydrogen transport in aluminium. The fact that the diffusion of hydrogen in aluminium is very small at room temperature makes it difficult to rationalize the effect of hydrogen on various properties which need a faster movement of hydrogen atoms. The argument that hydrogen can be transported by moving dislocations has recently received much attention (Speidel 1984; Tuck 1985; Watson and Meshii 1989) even though no conclusive evidence is available so far. Albrecht et al (1982) and Hardwick et al $(1982,1983)$ have reported for $\mathrm{Al}-\mathrm{Cu}(2124)$, $\mathrm{Al}-\mathrm{Zn}-\mathrm{Mg}$ (7050 and 7075) that the severity of hydrogen embrittlement varied when cathodic charging was conducted simultaneously with slow plastic straining (with a strain rate of $\sim 10^{-6} / \mathrm{sec}$ ). Feuerstein and John (1969) have used the outgassing behaviour of pure aluminium $(99.99 \%$ ) charged sample with and without strain to find a small amount of outgassing continuously with deformation. Both these studies concluded the dislocation transport of hydrogen as the reason for the observed effect. 


\section{Effect of hydrogen on the mechanical properties of aluminum and its alloys}

Effects of hydrogen on the mechanical properties of aluminium and its alloys will be discussed in this paper in terms of its embrittling nature and its role in stress corrosion cracking. Considerable amount of literature is available on the effects of hydrogen on the mechanical properties of aluminium and its alloys even though it is not that exhaustive as in the case of iron alloys (Gest and Troiano 1974; Scamans 1978; Christodoulou and Flower 1980; Albrecht et al 1982; Hardwick et al 1983; Tuck 1985; Wu-yang Chu et al 1985; Watson et al 1988). To start with, a work on $99.99 \%$ aluminium conducted by Watson et al (1988) showed an increase in the yield stress, a slight increase in the ultimate tensile strength and a decrease in the strain at failure with cathodic charging. But unlike high strength aluminium alloys, a large reduction in area due to hydrogen was not observed. Even after $72 \mathrm{~h}$ of charging, the samples failed in a completely ductile manner (Watson et al 1988).

Microhardness tests clearly indicated the effects of hydrogen where the hardness increased rapidly, saturating a pproximately"after $8 \mathrm{~h}$ (Watson et al 1988). But charging at lower cathodic current density (low hydrogen fugacities) showed somewhat slower saturation at lower saturation levels. But such a saturation limit was not observed on mechanical properties even after $72 \mathrm{~h}$ indicating that the bulk effects of hydrogen charging had not saturated within this duration. Depth profiling of hydrogen using microhardness across the sample revealed a severely hardened region near the charged surface and a less severely hardened region in the interior (Watson et al 1988). But charging for higher time scales had shifted the severely hardened region to higher hardness and to a greater depth.

The recovery characteristics of the surface hardened region were studied by annealing of $48 \mathrm{~h}$ charged samples in vacuum at $100,200,300,400$ and $500^{\circ} \mathrm{C}$ for $1 \mathrm{~h}$ with the surface microhardness measurements (Watson et al 1988). The profile was compared with the recovery behaviour of a sample cold rolled $(20 \mathrm{pct})$ to the same initial surface hardness. Recovery of the hydrogen charged sample occurred in two stages, the first one at around $300^{\circ} \mathrm{C}$ and the second stage at around $350^{\circ} \mathrm{C}$. But the cold rolled sample exhibited a single stage recovery at around $300^{\circ} \mathrm{C}$. The first stage recovery was attributed (Watson et al 1988) to the loss of the hardened surface layer since after the first stage recovery the surface and interior regions are having similar hardness. The second stage of recovery was coincident with the recovery stage of cold rolled aluminium. It was shown that (Watson et al 1988) the charging had increased the dislocation density. Thus it is reasonable to attribute the second stage of recovery to the annihilation of these dislocations. Therefore it is accepted that the two mechanisms producing hardening in cathodically charged aluminium are solute bydrogen and dislocation. TEM observations revealed higher dislocation densities in the charged samples $(48 \mathrm{~h})$ compared to the uncharged one. Dislocations were not uniformly distributed. The areas with straight parallel dislocations, high density dislocation bands and dislocation free regions were observed. The dislocation density was reported (Watson et al 1988) to be affected by grain orientation with respect to orientation of tharging surface while the orientation and structure of dislocation remain unaffected.

Effect of hydrogen on various high strength and medium strength alloys have been investigated by a number of investigators (Gest and Troiano 1974; Scamans 1978; Christodoulou and Flower 1980; Albrecht et al 1982; Hardwick et al 1983; Tuck 1985; Wu-yang Chu et al 1985; Bandyopadhyay et al 1992; 1994). In general, the hydrogen 
embrittlement was found to be dependent on temperature, strain rate and microstructure. Among aluminium alloys 7000 series alloys were the subject of many studies.

Hydrogen embrittlement caused intergranular fracture in these alloys. Another feature observed generally in $\mathrm{Al}-\mathrm{Zn}-\mathrm{Mg}$ alloys was the observation of striations showing that the crack propagation was discontinuous. Pre-exposure to humid air also caused reversible hydrogen embrittlement in $\mathrm{Al}-\mathrm{Zn}-\mathrm{Mg}$ alloys (Speidel 1971). The grain boundary precipitates like $\mathrm{MgZn}_{2}$ are reported (Scamans 1978; Christodoulou and Flower 1980; Tuck 1985) to be good trapping sites for hydrogen. Hydrogen bubbles associated with these particles were observed in a number of studies (Scamans 1978; Christodoulou and Flower 1980; Tuck 1985). These hydrogen bubbles at grain boundaries are not the direct cause of embrittlement but can induce fracture below the yield stress if present at boundaries which are saturated with hydrogen in solution. Data given in figure 1 show that both the stress dependent and stress independent crack velocities depend strongly on the water vapour content of the air (Speidel 1984). Christodoulou and Flower (1980) and Tuck (1985) have reported ductility decrease in $\mathrm{Al}-\mathrm{Zn}-\mathrm{Mg}$ alloys exposed to water vapour saturated air and observed a intergranular fracture surface. The effect of hydrogen was also reported to be dependent on reactivity of grain boundary (Tuck 1985). Aging and exposure to water vapour saturated air (WVSA) at $120^{\circ} \mathrm{C}$ for about $15 \mathrm{~h}$ showed a ductility increase and it was reported to be associated with a decrease in the reactivity of the grain boundary due to the production of $\mathrm{MgZn}_{2}$ (Tuck 1985).

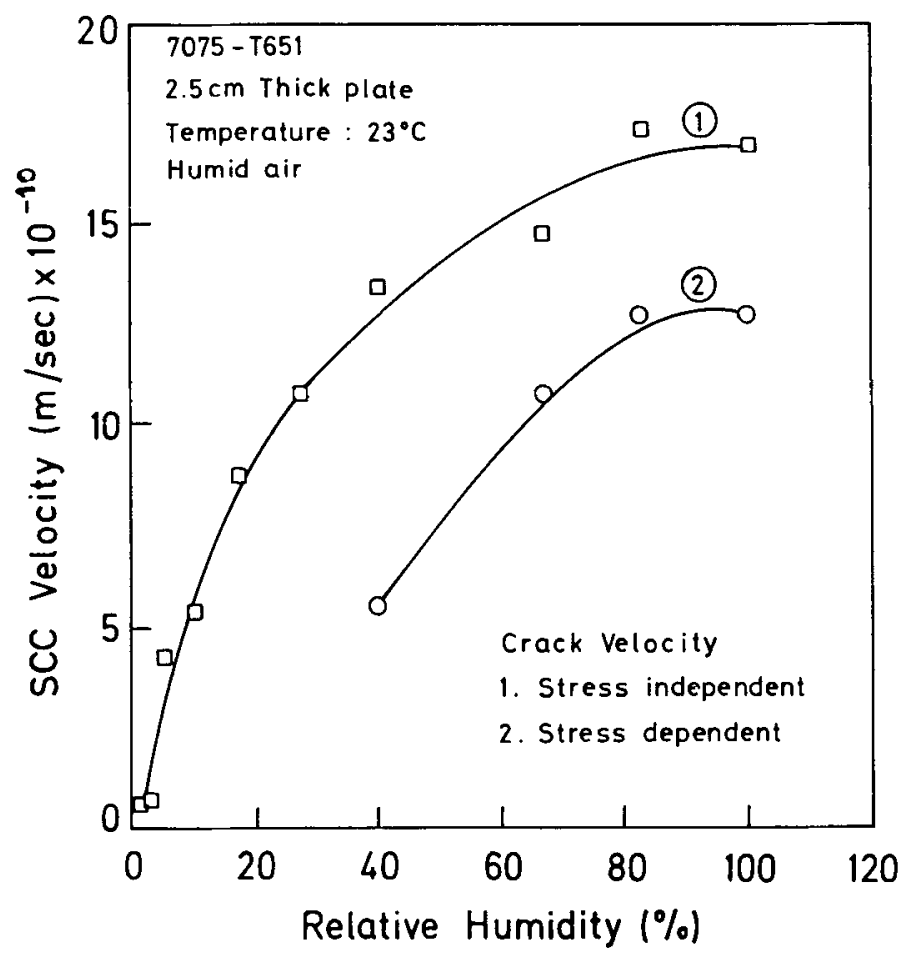

Figure 1. Variation of stress independent and stress dependent crack velocity as a function of water vapour content in air (Speidel 1984). 
Hydrogen induced reversible embrittlement has been reported in a newly developed alloy system; aluminium-lithium series (Balasubramanian and Duquette 1989; Shin et al 1989; Bandyopadhyay et al 1992, 1994). Cathodic charging of hydrogen caused a decrease in UTS, YS and elongation (figure 2) for 2091 and 8090 alloys. But the percentage reduction in area, which is also a measure of the ductility, was found to increase with charging time (figure 2). A transition in fracture mode from brittle mode at the surface to ductile failure at the centre was observed for the charged specimens. Microhardness measurements showed an increase in hardness with charging current density and the hardness decreased with depth (figure 3) (Bandyopadhyay et al 1992). In both cases the material was found to regain the hardness after degassing. Shin et al (1989) and Balasubramanian and Duquette (1989) have also reported similar behaviour for aluminium-lithium alloys. Unlike $\mathrm{Al}-\mathrm{Zn}-\mathrm{Mg}$ alloys, hydrogen caused a transgranular fracture in aluminium-lithium alloys.

\section{Role of hydrogen embrittlement in stress corrosion cracking}

Stress corrosion cracking (SCC) is defined as the joint action of stress and corrosive environment, eventually leading to fracture often at a stress level below the macroscopic yield stress of the material. The fracture mode under SCC condition can often be different from that observed without the corrosive environment. SCC has been investigated extensively since it was first reported in 1919 (Choo and Bernstein 1984). This phenomena was first reported in aluminium alloys in 1923 (Sander and Meissner 1923). Till that time the $\mathrm{Al}-\mathrm{Cu}-\mathrm{Mg}$ alloy, that could be described as a fore runner to the modern 2024 alloy, was in use for the rigid air ship, Zeppelin. In 1923, the very high

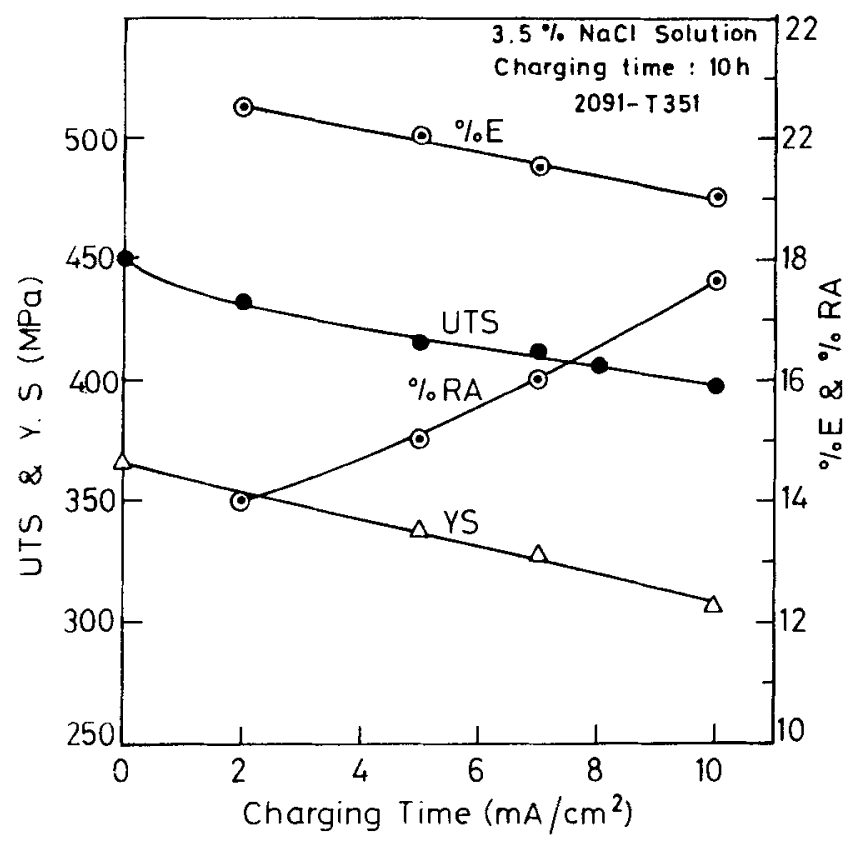

Figure 2. Varlation of UTS, YS, $\% \mathrm{E}$ and $\% \mathrm{RA}$ as a function of hydrogen charging time for aluminium- lithium alloys 2091-T351 (Bandyopadhyay et al 1992). 


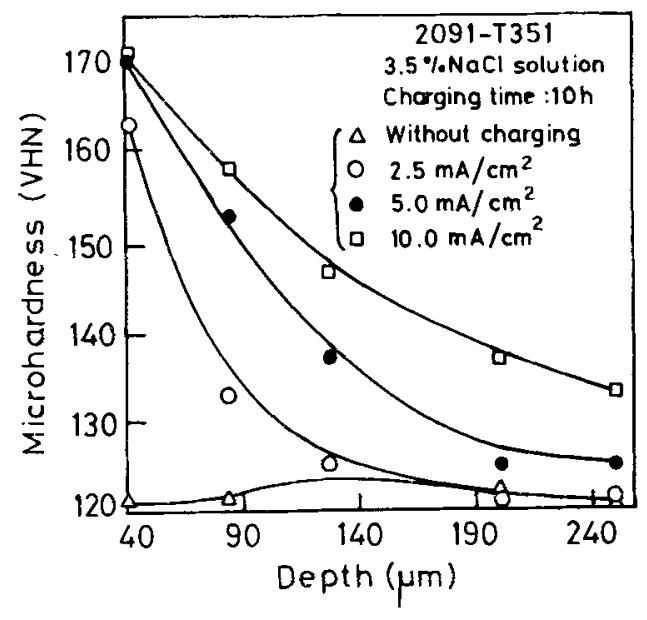

Figure 3. Variation of hardness as a function of depth for 2091 specimen charged at different current densitjes (Bandyopadhyay et al 1992).

strength $\mathrm{Al}-\mathrm{Zn}-\mathrm{Mg}$ alloys, fore runners to the modern 7000 series alloys, were developed (Sander and Meissner 1923). The first shipment of Al-Zn-Mg parts made for the Zeppelin factories was never used because the parts cracked during transport to the factory. The cracks were apparently caused by SCC under the combined influence of residual tensile stresses and the moisture of the air (Brenner 1962). Till then tremendous effort had been put by the researchers to understand this phenomenon in detail. Various reviews have appeared in the literature dealing with the SCC of aluminium alloys (Speidel 1971, 1984; Kruger 1980; Watson and Meshii 1989). Inspite of extensive investigation, no universal agreement has been reached on the operating mechanism for SCC. At least in all the discussions, two mechanisms dominate, they are: anodic dissolution (AD) and hydrogen embrittlement (HE). But in recent times there is growing evidence to suggest that HE mechanism takes a dominant role in the SCC of aluminium alloys (Troiano 1960; Speidel 1984).

\subsection{Anodic dissolution mechanism}

Anodic dissolution mechanism can be described as a preferential dissolution mechanism where the electrochemical reactions take control rather than hydrogen. This mechanism can be explained on the basis of the occurrence of three reactions in a growing crack (Doig and Flewitt 1977,1981). First is the cathodic reaction that occurs on the crack surface whereas the other two reactions are the bare surface or active anodic dissolution at the crack tip and the dissolution reaction of the oxide covered "passive crack" surfaces. The third reaction normally occurs at a constant current density i.e., it is independent of electrode potential but the first two reactions obey the normal tafel kinetics. The distribution of electrode potential in an advancing stress corrosion crack by an anodic metal loss at the plastically deforming crack tip has been reported earlier (Doig and Flewitt 1981). The potential gradient along the crack gives rise to an excess of cathodic current on the crack surfaces near the tip which 
complements the anodic dissolution at the crack tup (Dorg and Flewitt 1977, 1981). Equilibrium is established when the electrode potential at the crack tip produces an anodic current which is balanced by the total excess cathodic current on the crack surfaces. It is this electrode potential at the crack tip which controls the anodic dissolution and subsequent crack growth rate (Doig and Flewitt 1977, 1981). The stress (applied or residual) aids the process by opening up the crack, thereby continuously exposing virgin metal. From the explanation given above it is clear that eventhough the dissolution reaction can occur at any part of the metal, high-energy path like grain boundary may preferentially get dissolved because of its more anodic nature. Mueller et al (1985) have reported the presence of dissolution trenches parallel to the slip planes in specimens of 7075 loaded in mode III. Eventhough the anodic dissolution mechanism is still supported by many investigators to predict SCC growth (Dix 1940; Speidel 1975). mechanism with hydrogen embrittlement category has been gaining more popularity (Dix 1940; Thompson 1979; Thompson and Bernstein 1980). Since the present paper deals with the effect of hydrogen in aluminium and its alloys, a discussion on the latter will be dealt in detail. The description of the AD mechanism can be found elsewhere (Doig and Flewitt 1977, 1981).

\subsection{Hydroyen e'mbrittement merhanism}

In hydrogen embrittlement mechanism contrary to the anodic dissolution, the fracture or the crack growth occurs as a result of the hydrogen induced brittle region at the crack tip. The source of hydrogen is the cathodic reaction and the stress ahead of an advancing crack tip can accumulate abnormally high concentrations of hydrogen even though its diffusivity is less in aluminium (Troiano 1960; Oriani and Josephic 1972, 1974). Entry of hydrogen causes the production of a brittle region. This can occur in many ways among which decohesion (Oriani 1972), new phase formation (Troiano 1960) and pinning of dislocations (Latanision and Staehle 1968) are the most important. Crack propagates through the embrittled region and once the crack advances beyond the brittle zone, arrestation occurs. The hydrogen concentration then readjusts to the new stress distribution, diffusing again to the region of high stress ahead of the crack tip, and the entire process repeats (Watson and Meshii 1989).

A slight deviation of this mechanism was also popular where the greater reactivity of grain boundary is taken into consideration (Scamans 1978; Christodoulou and Flower 1980). Trapping of hydrogen at the grain boundary (migrated by diffusion mechanisms like bulk, dislocation-enhanced and grain boundary) decreases the cohesive strength between adjacent grains leading to embrittlement. This can be regarded as an extension of Troiano's model to the grain-boundary region. which is acting as the crack plane (Pathania and Tromans 1981).

Dependence of crack growth on various physical, chemical and environmental parameters is also in confirmity with the above mechanism. The environmental conditions, which affect the production process of hydrogen or conditions which enhance or inhibit the entry of hydrogen into the metal by the interposition or the reaction layer films, can influence the crack growth. Supporting this fact. subcritical urack growth in aluminium base alloys in many organic liquids is apparently the result of water in those liquids and thus there is a possibility of hydrogen embrittlement (figure 4) (Speidel 1984). As shown in figure 4, the crack growth rates measured in 


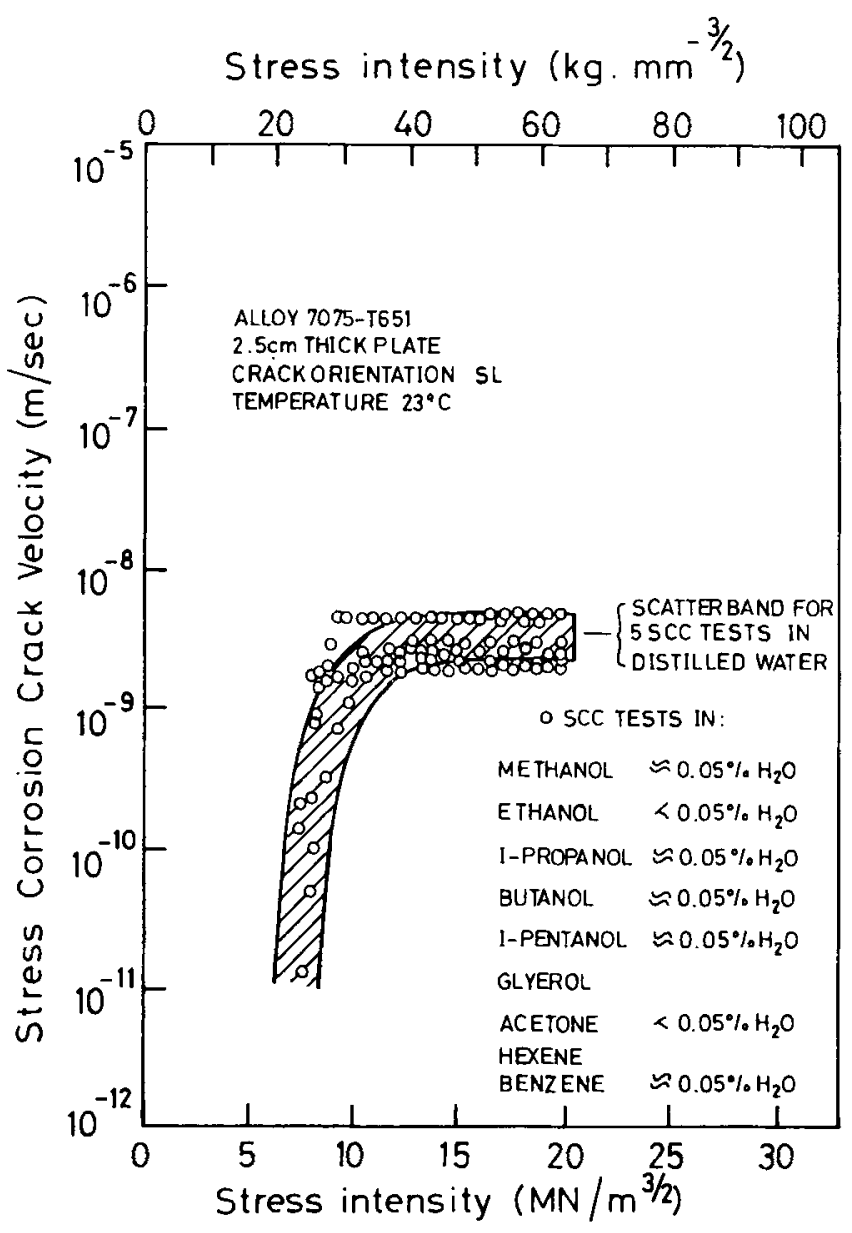

Figure 4. Effect of various organic liquids on subcritical crack growth in a high strength aluminium alloy (Speidel 1984).

organic liquids fall into the same scatterband of crack growth in water, humid hydrogen and humid air (Speidel 1984). In addition the crack growth was reported to be a function of the amount of water present in these liquids (Speidel and Hyatt 1972).

One of the discrepancies observed was the negligible effect of $\mathrm{pH}$ on crack growth rate. If the hydrogen embrittlement mechanism is applicable to the SCC of aluminium, one would expect the crack velocity to depend on the environmental hydrogen fugacity (Oriani 1972, 1978). But it has been found that only $\mathrm{pH}$ values below 3 enhanced the rate of crack growth (Speidel 1984). This apparent inconsistency is easily resolved by the fact that the $\mathrm{pH}$ values in cracks found in aluminium alloys in aqueous solution always remain around $3 \cdot 5$, even if the bulk solution has much higher $\mathrm{pH}$ value (Speidel and Hyatt 1972). So the negligible effect of $\mathrm{pH}$ on crack growth rate is not against the hydrogen embrittlement mechanism.

Another argument against HE mechanism is the beneficial effect of applied cathodic potential on SCC. As shown in figure 5, the stress dependent and the stress independent crack growth rates reach their maximum values as the potential shifts to more positive 


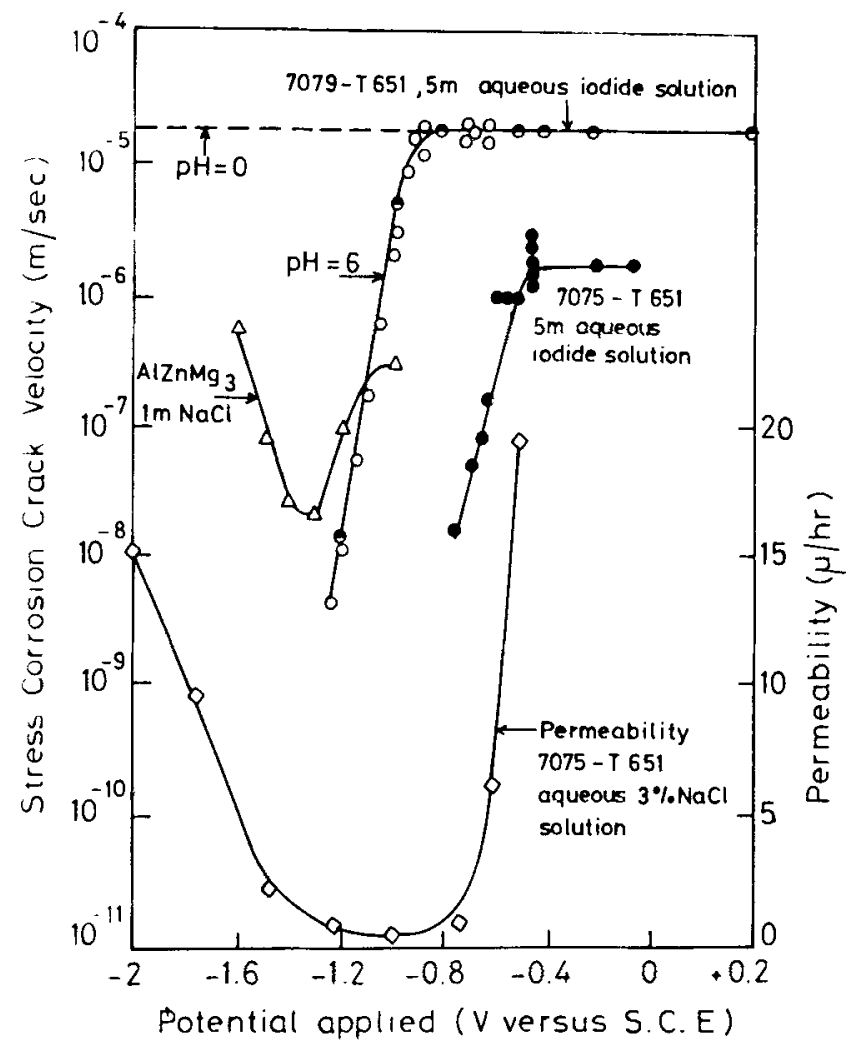

Higure 5. Effect of electrode potential on hydrogen permeability (Gest and Troiano 1974) and stress corrosion crack velocity in various aluminium alloys (Speidcl 1984).

values (Spendel 1984). Conversely, crack velocity is considerably reduced when the applied potential shifted to the negative side, though it is not expected from the general assumption that the higher cathodic potential generate more hydrogen. But the work of Gest and Troiano (1972) resolved this apparent discrepancy as illustrated in figure 5, where the hydrogen permeability through membranes of an aluminium alloy as well as SCC crack growth rates in various aluminium alloys at high stress intensities are plotted against the applied potential (Speidel 1984). Both hydrogen permeability and SCC growth rate exhibit a minimum at intermediate potentials. The increased hydrogen permeation and the parallel increase in crack growth rate towards more positive potentials could be rationalized as follows. Potentials that are more anodic than that corresponding to the minimum in the curves in figure 5 , gives rise to enhanced corrosion. dissolution, pitting and hence to the hydrogen evolution inside the crack (Speidel 1984). Corresponding to this, acid hydrolysis of the corrosion product is observed (Speidel and Hyatt 1972) and a large IR drop is expected down the crack. This facilitates hydrogen evolution reaction. Further, the cathodic protection against SCC at the intermediate potential can simply be attributed to a reduced dissolution (corrosion) rate in the crack with a concomitant reduction in the hydrogen evolution and a decrease in the IR drop down the crack (Speidel 1984).

Effect of temperature on the crack growth rate of aluminium alloys has been well documented in the literature. Increasing temperature results in high crack velocities 
(Speidel 1984), but it also provides a major clue for hydrogen embrittlement mechanism. Plotting of stress independent (plateau) crack growth rate versus the reciprocal temperature for 7039-T61 yields an apparent activation energy of $9 \mathrm{Kcal} / \mathrm{mole}$ (Speidel 1984), which is similar to the value found by Scamans et al (1976) $(\sim 8 \mathrm{Kcal} / \mathrm{mole})$ for the temperature dependence of the pre-exposure embrittlement of $\mathrm{Al}-\mathrm{Zn}-\mathrm{Mg}$ alloys in water vapour, that was attributed to hydrogen. Thus the rate limiting process is the hydrogen uptake of the alloy surface which can be strongly influenced by the surface condition.

Finally a note on the effect of loading mode. Certain alloys which are prone to hydrogen induced embrittlement have shown to be more susceptible in aqueous environment when loaded in tension (Mode I) than when loaded in torsion (mode III) (Green et al 1976; Latanision et al 1979). The reason for the decreased susceptibility under torsional loading according to hydrogen embrittlement mechanism is reported to be due to the lack of a hydrostatic component of stress to drive hydrogen into the region ahead of the crack tip (Green et al 1976). But this comparison should be done with caution as commercial aluminium alloys contain highly flattened grains.

\subsection{Cathodic charging and slow strain rate hydrogen embrittlement}

A strain aging type of hydrogen embrittlement in aluminium alloys has been demonstrated by Gest and Troiano (1972). These studies build the foundation to understand the role of hydrogen in SCC. Hydrogen precharging and subsequent tensile testing of high strength aluminium alloys showed ductility loss which was strain rate and temperature dependent. Increase in strain rates gradually reduces the ductility loss caused by hydrogen, until at very high strain rate there is essentially no influence of hydrogen. Moreover, these alloys showed the characteristic minimum ductility (maximum above $300 \mathrm{~K}$ ) with temperature. The effect increases rapidly to reach a maximum and then decreases rather slowly with decreasing temperature. The temperature for the maximum hydrogen embrittlement effect increased with strain rate. The effect of temperature and strain rate is attributed to the dislocation transport of hydrogen.

It is important to note that the ductility loss is recoverable and that the original ductility can be restored by outgassing of charged material at room temperature (Gest and Troiano 1972; Speidel 1974). Ohnishi (1987) has shown for Al-8\% Mg alloy that ductility loss with hydrogen precharging recovers with time. The charging introduced a loss of ductility by about $13 \%$ for a charging time of $1800 \mathrm{sec}$. But the loss of ductility was recovered by the subsequent aging of the charged specimens in dry air. Complete recovery was reported after 10 days. A similar type of behaviour was also reported for aluminium-lithium alloys (Bandyopadhyay et al 1992, 1994). A change in fracture mode was reported (Bandyopadhyay et al 1992, 1994) from intergranular mode in the hydrogen charged specimen to a fracture mode similar to that observed before hydrogen charging for the recovered specimens.

It is interesting to note that this kind of hydrogen embrittlement is not exclusively associated with grain boundaries. Gest and Troiano (1972) found transgranular cracking as a prominent fracture. It is also said that the effect of hydrogen is largest for the underaged condition and smallest for the overaged, thus following the pattern found for the susceptibility to SCC in high strength aluminium alloys (Leger and Piercy 1981; Albrecht et al 1982). 


\subsection{Hydrogen embrittlement versus anodic dissoiunon}

Even though there are numerous evidences cited above to support HE mechanism, whether or not SCC in aluminium base alloys in aqueous solution can be attributed to this mechanism is still a major unsolved question. It is just as easy to find arguments for a dissolution mechanism as it is to find arguments for a halide adsorption mechanism or for a mechanism involving hydrogen embrittlement or for a combination of several of the mechanisms. At present neither of the two mechanisms (HE or AD) alone can explain all the results of SCC. It is also possible that these two mechanisms may operate in parallel or series. Troiano's observation of hydrogen permeability and of reversible hydrogen embrittlement of aluminium alloys by cathodic charging in aqueous solution does show the dominance of $\mathrm{HE}$ mechanism in aluminium alloys, though $\mathrm{AD}$ mechanism cannot be generally discarded. In recent years there has been more evidence supporting a $\mathrm{HE}$ mechanism.

\section{Summary}

Eventhough the solubility and diffusion of hydrogen is small in aluminium and its alloys, it can be enhanced by trapping and the process of dislocation transport respectively. The presence of hydrogen degrades the mechanical properties of aluminium and its alloys. Also these alloys are found to be susceptible to reversible hydrogen embrittlement. Precharging of hydrogen embrittles these materials but the original properties can be regained by degassing for a long time. Eventhough the involvement of hydrogen embrittlement in SCC phenomenon is still a question of debate, HE mechanism gained more attention in recent years. In spite of there being various phenomena in support of HE mechanism, more understanding is necessary to resolve this issue.

\section{References}

Albrecht J, Bernstein I M and Thompson A W 1982 Met. Truns. A13 811

Balasubramanian R and Duquette D J 1989 in Proc. of fifth int. aluminium lithium conf., Williamshurg. Virginia, (eds) T H Sanders Jr and E A Starke Jr, Vol. III, p. 1271

Bandyopadhyay A, Ambat R and Dwarakadasa E S 1992 Bull. Mater. Sci. 15311

Bandyopadhyay A, Ambat R and Dwarakadasa E S 1994 in Metallic corrosion principles and control, (eds) A S Khanna, S N Malhotra, K S V Santhanam and M K Totlani (New Delhi: Wiley Eastern Limited) p. 13 Besenbacher F. Myers S M and Norskov J K cited by Ishikawa T and McLellan R B 1986 Acta Metall.341093 Brenner P 1962 Aluminium 3843

Choo W Y and Bernstein I M 1984 Met. Trans. A15 1953

Christodoulou L and Flower H M 1980 Acta Metall. 28481

Csanady A, Papp K and Pasztor E 1981 Mater. Sci. \& Eng. 4835

Dix E H Jr 1940 Trans. AIME 13711

Doig P and Flewitt P E J 1977 Proc. R. Soc. London A357 439

Doig P and Flewitt P E J 1981 Met. Trans. A12 923

Edwards R A H and Eichenauer W 1980 Scr. Metall. 14971

Eichenauer W. Hattenbach K and Pebler A 1961 Zeit. Metall. 52682

Eichenauer W and Pebler A 1957 Z. Metall. 48375

Feverstein S and John J W 1969 J. Appl. Phys. 403334

Foster L. M, Jack T H and Hill W W 1970 Met. Trans. A1 3117

Gest R J and Troiano A R 1972 in L. Hydrogene dans Les Metaux (Paris: Edition Science et Industrie) p. 427

Gest R J and Troiano A R 1974 Corrosion 30274 
Green J A S, Hayden H W and Montague W G 1976 in Effect of hydrogen on behatiour of malenals, (New York: AIME) p. 200

Hardwick D A, Taberi M, Thompson A W and Bernstein I M 1982 Met Trans. A13 235

Hardwick D A, Thompson A W and Bernstein I M 1983 Met Trans. A14 2517

Hashimoto E and Kino T 1983 J. Phys. F, Met. Phy. 131157

Ichimura M, Imabayashi M and Hayakawa M 1980 J. Jap. Inst. Met. 441053

Ishikawa T and McLellan R B 1986 Acta Metall. 341091

Kruger J 1980 in Stress corrosion cracking (eds) J Yahalom and A Aladjem (Israel: Freund Publishing House) p. 4

Latanision R M, Gastine O H and Compeau C R 1979 in Environment sensitive fracture of engineering materials (New York: AIME) p. 48

Latanision R M and Staehle R W 1968 Scr. Metall. 2667

Leger M and Piercy G R 1981 Philos. Mag. 43377

Matsuo S and Hirata T 1967 J. Jap. Inst. Met. 31590

Mueller M P, Bernstein I M and Thompson A W 1985 Corrosion 41127

Ohnishi T 1987 Bull. Jap. Inst. Met. 26389

Opie W R and Grant N J 19501881237

Oriani R A 1972 Ber. Bunsen Gesell.f. Phys. Chemic. 76848

Oriani R A 1978 A decohesion theory of hydrogen induced crack propayation in stress corrosion and hydrogen embrittlement of iron base alloys (Houston, TX: NACE)

Oriani R A and Josephic P H 1972 Scr. Metall. 6681

Oriani R A and Josephic P H 1974 Acta Metall. 221065

Outlaw R A, Peterson D T and Schmidt F A 1982 Scr. Metall. 16277

Papp K and Kovacs-Cseteny E 1977 Scr. Metall. 11921

Papp K and Kovacs-Cseteny E 1981 Scr. Metall. 15161

Pathania R S and Tromans D 1981 Met. Trans. A12 607

Peisl H 1978 Topics in applied physics: Hydrogen in metals I, (eds) G Aiefeld and J Vokl (Berlin: Springerveriag) p. 53

Ransley C E and Neufeld H 1948 J. Inst. Met. 74599

Sander W and Meissner K L 1923 Z. Metall. 15180,1612

Scamans G M 1978 J. Mater. Sci. 1327

Scamans G M, Alani R and Swann P R 1976 Corrosion Sci. 16443

Shahani H 1985 Scand. J. Met. 14306

Shin K S, Kim S S and Lee E W 1989 in Proc. of fifth int aluminium-lithium conf., Williamshurg, Virginia, (eds) T H Sanders Jr and E A Starke Jr (Materials and Component engg. Publications Ltd.) Vol. III, p 1319

Speidel M O 1971 in The theory of stress corrosion cracking in alloys (Brussels: Natio Scientific Affairs Division) p. 289

Speidel M O 1974 in Hydrogen in metals (eds) I M Bernstein and A W Thompson (Metals Park, Ohio: American Society for Metals) p. 249

Speidel M O 1975 Met. Trans. A6 631

Speidel M O and Hyatt M V 1972 in Advances in corrosion science and technology (New York-London: Plenum Press) Vol. 2, p. 115

Speidel M O 1984 in Hydrogen embrittlement and stress corrosion cracking (eds) R Gibala and R F Hehemann (Metals Park, Ohio: Am. Soc. for Metals) p. 271

Talbot D E J 1975 Int. Mater. Rev. 20166

Thompson A W 1979 in Environment-sensitive fracture of engineering materials, (ed) Z A Foroulis (Warrendale, Pennsylvania: The Metallurgical Society of AIME) p. 379

Thompson A W and Bernstein I M 1980 Adv. Corrosion Sci. \& Technol. 753

Tiwari S N, Gupta A K and Malhotra S L 1986 The Brit. Found. 129

Troiano A R 1960 Trans. ASM 5254

Tuck C D S 1985 Met. Trans. A16 1503

Watson J W and Meshii M 1989 in Treatise of materials science and technology, p. 501

Watson J W, Shen Y Z and Meshii M 1988 Met. Trans. A19 2299

Wu-Yang Chu, Chi-Mei Hsiao and Jun-wen Wang 1985 Met. Trans. A16 1663 